Purdue University

Purdue e-Pubs

CTRC Research Publications

Cooling Technologies Research Center

2004

\title{
Transport in Flat Heat Pipes at High Heat Fluxes from Multiple Discrete Sources
}

U.Vadakkan

S V. Garimella

Purdue University, sureshg@purdue.edu

J.Y.Murthy

Follow this and additional works at: http://docs.lib.purdue.edu/coolingpubs

Vadakkan, U.; Garimella, S V.; and Murthy, J. Y., "Transport in Flat Heat Pipes at High Heat Fluxes from Multiple Discrete Sources" (2004). CTRC Research Publications. Paper 274.

http://dx.doi.org/10.1115/1.1737773

This document has been made available through Purdue e-Pubs, a service of the Purdue University Libraries. Please contact epubs@purdue.edu for additional information. 


\section{Transport in Flat Heat Pipes at High Heat Fluxes From Multiple Discrete Sources}

\section{Unnikrishnan Vadakkan Suresh V. Garimella Jayathi Y. Murthy}

Cooling Technologies Research Center, School of Mechanical Engineering, Purdue University, West Lafayette, IN 47907-2088
A three-dimensional model has been developed to analyze the transient and steady-state performance of flat heat pipes subjected to heating with multiple discrete heat sources. Three-dimensional flow and energy equations are solved in the vapor and liquid regions, along with conduction in the wall. Saturated flow models are used for heat transfer and fluid flow through the wick. In the wick region, the analysis uses an equilibrium model for heat transfer and a Brinkman-Forchheimer extended Darcy model for fluid flow. Averaged properties weighted with the porosity are used for the wick analysis. The state equation is used in the vapor core to relate density change to the operating pressure. The density change due to pressurization of the vapor core is accounted for in the continuity equation. Vapor flow, temperature and hydrodynamic pressure fields are computed at each time step from coupled continuity/momentum and energy equations in the wick and vapor regions. The mass flow rate at the interface is obtained from the application of kinetic theory. Predictions are made for the magnitude of heat flux at which dryout would occur in a flat heat pipe. The input heat flux and the spacing between the discrete heat sources are studied as parameters. The location in the heat pipe at which dryout is initiated is found to be different from that of the maximum temperature. The location where the maximum capillary pressure head is realized also changes during the transient. Axial conduction through the wall and wick are seen to play a significant role in determining the axial temperature variation. [DOI: 10.1115/1.1737773]

Keywords: Electronics, Heat Pipes, Phase Change, Three-Dimensional, Transient

\section{Introduction}

Heat pipes are widely used in electronics cooling applications, both as efficient heat spreaders and to transport heat to remote heat sinks for dissipation. The analysis of the operation and performance of heat pipes has received a lot of attention, as reviewed in Garimella and Sobhan [1]. For the most part, attention has been focused on the study of either flat or round heat pipes, typically with single heat sources. Recently, there has been increased interest in exploring the use of flat heat pipes as substrates upon which multiple heat generating components would be mounted. In such a configuration, the heat pipe acts both as a heat spreader as well as a conveyer of heat, while also providing the mechanical substructure. The performance of flat heat pipes under these types of heterogeneous and distributed loads is not well understood and forms the subject of the present study.

A number of steady-state analyses of heat pipes, mostly with single heat sources, have been published. Tien and Rohani [2] investigated the effects of vapor pressure distribution on vapor temperature in a cylindrical heat pipe with a single heat source using a stream function vorticity formulation. The analysis indicated that in certain situations the vapor pressure variation plays a significant role in the performance of heat pipes; this work assumed a constant datum pressure at the liquid-vapor interface at the end of the evaporator section. Approximate solutions based on parabolic boundary layer equations were shown to yield inaccurate predictions of the vapor pressure variation at high evaporation and condensation rates. Van Ooijen and Hoogendoorn [3] presented a steady two-dimensional numerical analysis of the vapor core in a horizontal flat heat pipe. The computations were performed at different radial Reynolds numbers and the results were compared with a porous plate model. Though interesting insights

Contributed by the Heat Transfer Division for publication in the JOURNAL OF HEAT TRANSFER. Manuscript received by the Heat Transfer Division June 30, 2003; revision received February 6, 2004. Associate Editor: J. H. Lienhard V. into vapor flow patterns were presented, the study did not consider coupled wick/vapor flow, and the evaporator/condenser mass flow rate was assumed to be known a priori. Chen and Faghri [4] studied both single and multiple heat sources, albeit in a twodimensional axi-symmetric cylindrical heat pipe. A coupled analysis of the wall, wick and vapor regions was conducted. Both sodium and water were considered as the working fluids. The solutions are compared against experimental results for the vapor and wall temperature at high and low operating temperatures. For the operating conditions considered, compressibility effects were found to be very important.

Unsteady analyses of heat pipe operation have also been published. Issacci et al. [5] analyzed the transient behavior of vapor flow in heat pipes, taking vapor pressurization into account in determining the change in vapor density. The absolute pressure of the vapor was used as the interface pressure in calculating the temperature at the interface from the saturation condition, and the pressure difference between the vapor and the interface to allow for vaporization or condensation at the interface was not considered. The analysis studied the effect of input heat flux and condensation temperature on vapor core response. Transient twodimensional computations of cylindrical heat pipes including the wick, vapor and wall were performed by Cao and Faghri [6]. A compressible flow formulation was used to account for the pressurization of the vapor during the transient. The study also investigated the transient response of heat pipes to a pulsed heat input. Issacci et al. [7] studied vapor dynamics during heat pipe start-up. The analysis neglected the convection through the liquid wick and conduction through the wall. The liquid flow in a homogeneous wick heat pipe was studied by Ambrose and Chow [8]. The transient axial distribution of liquid in the wick was analyzed and the results compared to experiments. Dryout was observed when the heat transport was greater than the capillary limit. Tournier and El-Genk [9] developed a two-dimensional model for the transient analysis of heat pipes. The analysis determined the radius of cur- 
vature of the liquid meniscus at the liquid-vapor interface. A model for liquid pooling was included. The study assumed a constant temperature in the vapor core. The results were compared to experiments which studied the effect of inclination on the transient performance of heat pipes [10]. The experiments provided temperatures on the wall and the vapor core of the heat pipe in the axial direction. Zhu and Vafai [11] studied the start-up transients in an asymmetrical flat heat pipe, using transient heat conduction equations for the heat pipe wall and wick, and a pseudo-threedimensional approximation in the vapor region. More recent experimental and numerical analyses of heat pipe performance may be found in [12-18].

Although these studies have established useful models and methodologies for the steady as well as transient simulation of thermal transport in heat pipes, sound models representing flat heat pipe performance under transient conditions and with multiple discrete heat sources on the evaporator section are not readily available.

In recent work by the authors [19], a complete two-dimensional mathematical model was developed to analyze the transient and steady-state performance of flat heat pipes. The model accounted for the pressurization of the vapor core and the coupling of the continuity, momentum and energy equations in the wick and vapor regions. A stable numerical procedure was devised to solve the resulting governing equations. The procedure improved upon the standard sequential solution scheme by recognizing the sensitivity of the mass flow rate at the phase change interface to the interface temperature and pressure, as well as the system pressure. The improved method was shown to perform well over a range of heat inputs, and the predictions showed satisfactory agreement with experiments.

The present work utilizes the numerical method developed in [19] to study the performance of flat heat pipes with multiple discrete heat sources. The effect of heat source strength and separation and their effect on steady as well as transient performance are studied. The simulations are used to assess the possibility of dryout as well as the location at which dryout might first be observed. The maximum pore radius necessary to support the pressure drop at the evaporator interface is obtained from the hydrodynamic pressure variation at the interface.

\section{Mathematical Model}

The present three-dimensional analysis includes the liquid wick and the wall in addition to the vapor core. An equilibrium model for heat transfer and a Brinkman-Forchheimer extended Darcy model for fluid flow in the wick region are employed. The density change in the vapor due to pressurization is calculated using the ideal gas state equation. The mass flow rate, temperature and pressure at the interface are determined using an energy balance at the interface in conjunction with kinetic theory and the ClausiusClapeyron equation. The energy balance at the interface includes convection and conduction on the liquid and vapor sides. Vapor flow, temperature and hydrodynamic pressure fields are computed from coupled continuity/momentum and energy equations in the vapor and wick regions, and a conduction analysis in the wall. The flow of the vapor is assumed as laminar and incompressible. At high heat fluxes, the vapor velocity may be high enough for compressibility effects to become important; these are not accounted for in the present development. Compressibility effects are being included in the formulation as part of ongoing work.

The boundary conditions are of the Neumann type on the evaporator side and of mixed type at the condenser. The model assumes that the wick is saturated with liquid throughout, which is required to prevent dryout. The initial volume fraction of the liquid in the wick is 0.5 (liquid-saturated wick). If the wick were not fully saturated with liquid, vapor would occupy the unsaturated portion of the wick. Estimates of the force needed to expel this trapped vapor from the liquid show it to be significant compared to the force required to move liquid from the condenser to the

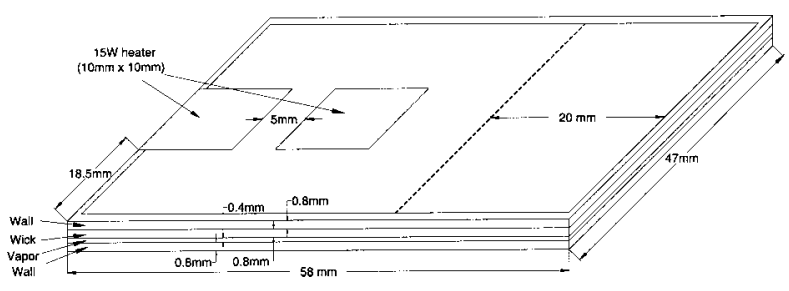

Fig. 1 Schematic diagram of the flat heat pipe investigated; the thickness dimension has been greatly exaggerated in this schematic to delineate the different parts of the heat pipe

evaporator. As a result, dryout would occur as soon as vapor displaces the liquid in the wick. This unsaturated condition need not be considered for prediction of the onset of dryout.

The physical dimensions of the flat heat pipe investigated are shown in Fig. 1. The heat pipe dimensions, $47 \mathrm{~mm}$ width and 58 mm length with a wall thickness of $0.8 \mathrm{~mm}$ on all six sides, simulate those of typical commercially available flat heat pipes. The condenser covers $20 \mathrm{~mm}$ of the heat pipe as shown in the figure. The wall and wick are made of copper and the working fluid is water. The porosity, permeability and thermal conductivity of the sintered copper wick are $0.5,1.43 \times 10^{-11} \mathrm{~m}^{2}$, and 40 $\mathrm{W} / \mathrm{mK}[20]$, respectively. The wick is present only on one side of the heat pipe, and the heating and cooling boundary conditions are applied only on this wicked side. Two discrete $10 \times 10 \mathrm{~mm}$ heat sources are mounted at a separation distance of $5 \mathrm{~mm}$ in the baseline case. The heat input to each heat source is $15 \mathrm{~W}$. Those portions of the heat pipe surface not exposed to the condenser or evaporator boundary conditions are assumed adiabatic. The thermophysical properties of the heat pipe wall, wick and vapor core are given in Table 1. The coolant water temperature and the heat transfer coefficient on the condenser are $287 \mathrm{~K}$ and $2604 \mathrm{~W} / \mathrm{m}^{2} \mathrm{~K}$, respectively. The initial temperature all through the heat pipe is $287 \mathrm{~K}$ and the vapor is assumed to be saturated.

To accommodate changes in the vapor and liquid mass during the transient under the assumption of a liquid-saturated wick, the mass balance of the liquid is handled by modifying the volumeaveraged density of the liquid in the wick. All thermophysical properties are assumed constant except for the vapor density, which is found from the operating pressure $P_{o p}$ and the local temperature using the perfect gas law. Under these assumptions, the governing equations may be written as shown below, following the development in [19]. The continuity equation for the wick and the vapor core is

$$
\varphi \frac{\partial \rho}{\partial t}+\nabla \cdot(\rho V)=0
$$

The term $\partial \rho / \partial t$ accounts for mass addition or depletion in the vapor and liquid spaces. The three-dimensional momentum equations in the wick and the vapor core are

Table 1 Thermophysical properties of the heat pipe material and the working fluid

\begin{tabular}{lll}
\hline \hline Copper & Thermal conductivity & $401 \mathrm{~W} / \mathrm{m} \mathrm{K}$ \\
wall/wick & Specific heat & $385 \mathrm{~J} / \mathrm{kg} \mathrm{K}$ \\
& Density & $8933 \mathrm{~kg} / \mathrm{m}^{3}$ \\
\multirow{4}{*}{ Water } & Wick conductivity & $40 \mathrm{~W} / \mathrm{m} \mathrm{K}$ \\
& Thermal conductivity & $0.6 \mathrm{~W} / \mathrm{m} \mathrm{K}$ \\
& Specific heat & $4200 \mathrm{~J} / \mathrm{kg} \mathrm{K}$ \\
& Density & $1000 \mathrm{~kg} / \mathrm{m}^{3}$ \\
\multirow{2}{*}{ Water vapor } & Viscosity & $8 \times 10^{-4} \mathrm{~N} \mathrm{~s} / \mathrm{m}^{2}$ \\
& Thermal conductivity & $0.0189 \mathrm{~W} / \mathrm{m} \mathrm{K}^{2}$ \\
& Specific heat & $1861.54 \mathrm{~J} / \mathrm{kg} \mathrm{K}$ \\
& Density & $0.01 \mathrm{~kg} / \mathrm{m}^{3}$ \\
Water/Vapor & Viscosity & $8.4 \times 10^{-6} \mathrm{~N} \mathrm{~s} / \mathrm{m}^{2}$ \\
& Latent heat & $2473 \mathrm{~kJ} / \mathrm{kg}$ \\
\hline \hline
\end{tabular}




$$
\begin{gathered}
\frac{\partial \rho u}{\partial t}+\nabla \cdot(\rho V u)=-\frac{\partial \varphi p}{\partial x}+\nabla \cdot(\mu \nabla u)-\frac{\mu \varphi}{K} u-\frac{C_{E} \varphi}{K^{1 / 2}} \rho|V| u \\
\frac{\partial \rho v}{\partial t}+\nabla \cdot(\rho V v)=-\frac{\partial \varphi p}{\partial y}+\nabla \cdot(\mu \nabla v)-\frac{\mu \varphi}{K} v-\frac{C_{E} \varphi}{K^{1 / 2}} \rho|V| v \\
\frac{\partial \rho w}{\partial t}+\nabla \cdot(\rho V w)=-\frac{\partial \varphi p}{\partial z}+\nabla \cdot(\mu \nabla w)-\frac{\mu \varphi}{K} w-\frac{C_{E} \varphi}{K^{1 / 2}} \rho|V| w
\end{gathered}
$$

In the vapor core, permeability $K=\infty$ and porosity $\varphi=1$. The energy equation in the wall, wick and the vapor core is

$$
\frac{\partial(\rho C)_{m} T}{\partial t}+\nabla \cdot[(\rho C) V T)=\nabla \cdot\left(k_{\mathrm{eff}} \nabla T\right)
$$

Here, $(\rho C)_{m}$ assumes different values in the wall, wick, and vapor core

$$
\begin{gathered}
\text { Wall: }(\rho C)_{m}=(\rho C)_{s} \\
\text { Wick: }(\rho C)_{m}=(1-\varphi)(\rho C)_{s}+\varphi(\rho C)_{l} \\
\text { Vapor core: }(\rho C)_{m}=(\rho C)_{v}
\end{gathered}
$$

Also, $k_{\text {eff }}$ is the effective conductivity in the region of interest and assumes appropriate values in the wall, wick and vapor core. In the wick, an effective value of $40 \mathrm{~W} / \mathrm{mK}$ is assumed [20]. [19].

The following boundary conditions are imposed on the domain

1. Wick-Vapor Interface: Change of phase from liquid to vapor is assumed to occur at the wick-vapor core interface (Fig. 1). The interface temperature $T_{i}$ is obtained from the energy balance at the interface

$$
-k_{\text {wick }} A_{i} \frac{\partial T}{\partial y}+m_{i} C_{i} T_{i}=-k_{v} A_{i} \frac{\partial T}{\partial y}+m_{i} C_{v} T_{i}+m_{i} h_{f g}
$$

Here, $m_{i}<0$ denotes evaporation, and $m_{i}>0$ denotes condensation. The interface pressure $P_{i}$ is obtained from the ClausiusClapeyron equation, with $P_{0}$ and $T_{0}$ being reference values

$$
\frac{R}{h_{f g}} \ln \left(\frac{P_{i}}{P_{0}}\right)=\frac{1}{T_{0}}-\frac{1}{T_{i}}
$$

The interface mass flux is calculated using kinetic theory [21]

$$
\left(\frac{2 \sigma}{2-\sigma}\right)\left(\frac{1}{(2 \pi R)^{1 / 2}}\right)\left(\frac{P_{v}}{\left(T_{v}\right)^{1 / 2}}-\frac{P_{i}}{\left(T_{i}\right)^{1 / 2}}\right)=m_{i}^{\prime \prime}
$$

A value for $\sigma$ of 0.03 [21] is used in this work. The evaporated and condensed mass is assumed to flow normal to the interface when accounting for momentum transport due to evaporation/ condensation. In the present formulation, no attempt is made to track the free surface; as a result entrainment effects cannot be computed. Since the velocity computed in the wick region is averaged over both fluid and solid, the mean tangential velocity in the wick at the wick/vapor interface is approximately zero.

2. Wick-Wall and Vapor-Wall Interface: $u=0, \nu=0$

3. Top Wall:

$$
\text { Evaporator section: } k_{w} \frac{\partial T}{\partial y}=q_{e} \quad 0 \leqslant x \leqslant L_{e}
$$

Adiabatic section: $\frac{\partial T}{\partial y}=0 \quad u=v=0, \quad L_{e} \leqslant x \leqslant L_{e}+L_{a}$ Condenser section: $-k_{w} \frac{\partial T}{\partial y}=h_{c}\left(T-T_{c}\right) \quad x>L_{e}+L_{a}$

4. Lateral Walls: $u=v=\partial T / \partial x=0$

5. $\overline{\text { Bottom Wall: }} u=v=\partial T / \partial y=0$

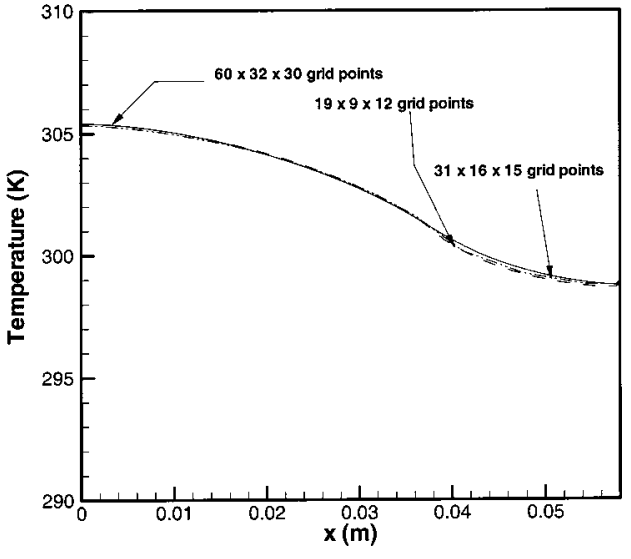

Fig. 2 Steady-state axial wall temperature variation for different mesh sizes at 15-15 W input power $(z / W=0)$

In addition, the following initial conditions are imposed: $T(x, y, 0)=T_{i}$ and $P_{o p}(t=0)=P_{\text {sat }}\left(T_{i}\right)$.

Details of the numerical method may be found in [19]. The governing equations are discretized using the finite volume method. The SIMPLE algorithm [22] with a collocated grid is employed. An up-winding scheme is implemented for the convective flux and central differencing for the diffusive flux. The linear equations resulting from the discretization are solved by a lineby-line TDMA. An Euler implicit scheme is used for time differencing.

A variety of tests were run to establish mesh and time-step independence. A baseline case with a heat input to the left and right heat sources of $15 \mathrm{~W}$ each (henceforth denoted as $15-15 \mathrm{~W}$ for the left-right values) was used. Three different meshes $(x \times y$ $\times z$ ) were evaluated: $19 \times 9 \times 12,31 \times 16 \times 15$, and $60 \times 32 \times 30$. The dependence of the evaporator wall temperature on the mesh size is shown in Fig. 2. The results indicate that changing the number of grids from $19 \times 9 \times 12$ to $60 \times 32 \times 30$ changes the wall temperature by 0.10 percent. The corresponding average difference in the total evaporator mass flow rate was 1.22 percent at steady state. As a result of this grid-independence study, the 31 $\times 16 \times 15$ mesh was used for all the results shown here; the wall, wick and vapor regions include 8,4 , and 4 grid points, respectively, in the $y$-direction. Similar tests varying the time step indicate that a time step of $1 \mathrm{~s}$ is adequate. The attainment of steady state is identified in this work as the time at which the heat transfer rate on the condenser side reaches within $0.1 \%$ of the value at the evaporator. Within each time step, the computations are stopped when the sum of the absolute values of the residuals for temperature, $u, v$, and $w$ velocities are less than or equal to $10^{-11}$.

\section{Results and Discussion}

The transient variation of wall temperature under the center of the far-left heater is shown in Fig. 3. The heat flux supplied to the two heat sources is varied while the heat source separation is held constant at $5 \mathrm{~mm}$. The numerical results reveal a time constant for the heat pipe under consideration to be $6 \mathrm{~s}$. This compares well to an estimated response time of the system from a lumped capacitance analysis of $7.1 \mathrm{~s}$. The relatively low time constant results from the small thermal mass of the heat pipe and the relatively high heat transfer coefficient at the condenser (achieved in the experiments with a cooling water jacket). The time constant is independent of the heat flux applied at the evaporator.

It is clear from Fig. 3 that the temperature under the left heater decreases as its heat input is reduced from 15 to $5 \mathrm{~W}$. In all three cases, the system reaches a steady state at $100 \mathrm{~s}$, independent of the heat input. The transient variation of heat transfer rate on the condenser side for the three different sets of heat input is shown in 


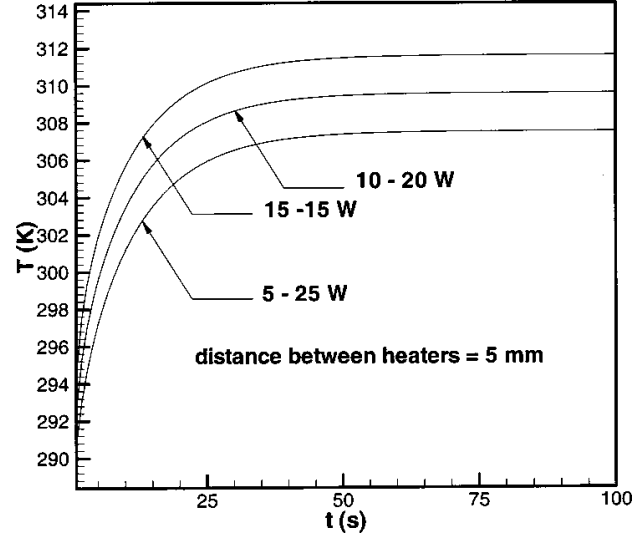

Fig. 3 Transient wall temperature under the far-left heater $(x / L=0.093, y / H=1, z / W=0.5)$ for different power input combinations to the two heaters

Fig. 4. It is clear from the figure that the condenser heat transfer rate is the same for all three distributions of heat input.

Contours of the wall temperature variation on the wicked side of the heat pipe $(y=2.8 \mathrm{~mm})$ at steady state are shown in Fig. 5. The baseline case is again considered, with equal heat inputs to the two sources. As observed earlier, the maximum temperature occurs at the center of the heat source on the left. Conduction down the side wall is responsible for the maximum temperature

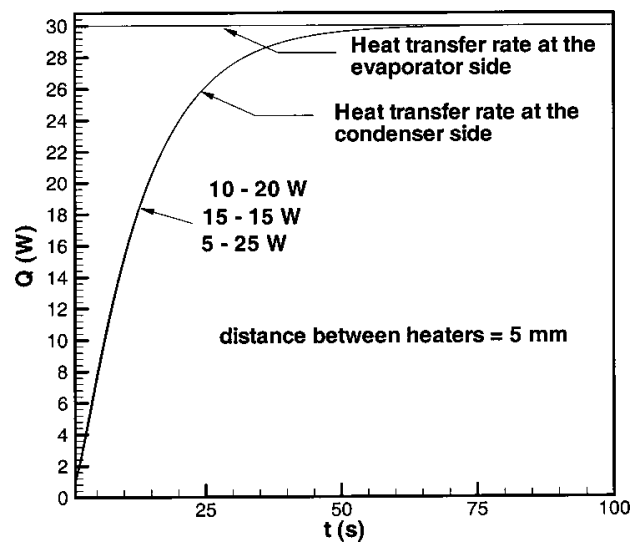

Fig. 4 Transient variation of the heat removal rates at the evaporator (constant $\left.Q_{\text {in }}\right)$ and condenser $\left(Q_{\text {out }}\right)$ sections for the three heat input combinations

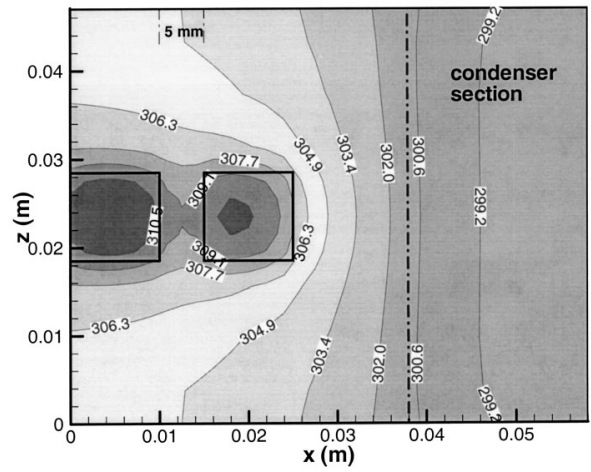

Fig. 5 Temperature contours at the wall $(y / H=1)$ on the wicked side of the heat pipe at an input power of 15-15 W: the condenser section is delineated by the dashed line.

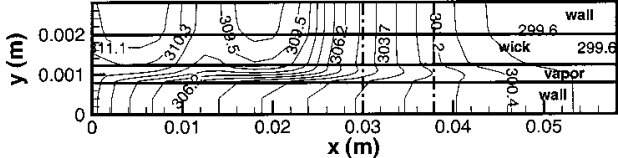

Fig. 6 Temperature distribution at the mid plane $(z / W=0.5)$ of the heat pipe for the baseline case with 15-15 $\mathrm{W}$ heat input $(d=5 \mathrm{~mm})$

not occurring at the left end of this heat source. The temperature decreases with distance away from the heated zone.

The temperature distribution along the vertical midsection $(z$ $=23.5 \mathrm{~mm}$ ) of the heat pipe is shown in Fig. 6. Again, the highest temperatures are in the vicinity of the discrete heat sources. In the vapor region, a significant drop of $12^{\circ} \mathrm{C}$ in temperature along the axial direction is observed, indicating continual energy transfer into the vapor across the liquid-vapor interface. In cases where the effect of convection in the vapor may be dominant over diffusion at the liquid-vapor interface, the vapor temperature variation would be significantly smaller. The Peclet number $\left(\rho u C_{p} H_{v} / k\right.$ $\sim 10-20$ in the present work) of the vapor space governs which of these processes is dominant. The figure also shows a significant drop in temperature through the wick ( $y$-direction), attributable to the low wick thermal conductivity.

The velocities in the wick and vapor core at steady state are shown in Fig. 7. It is clear that there is no "adiabatic" section inside the heat pipe. The $v$-velocities at the liquid-vapor interface allow a delineation of the actual length of the evaporator and condenser regions at the wick-vapor interface. In the vapor core, the velocity increases in the evaporator region along the axial direction because of mass addition from the interface; similarly, the velocity decreases in the condenser region along the axial direction because of mass depletion. The average liquid velocity is much smaller than the average vapor velocity because of the large differences in density. The analysis also shows that there is no region in the liquid-vapor interface where the interfacial velocity is zero.

Figure 8 shows the transient variation of liquid and vapor pressure drop at the liquid-vapor interface. The pressure drop at any point is calculated by subtracting the absolute pressure at the right end of the condenser section from the actual pressure at the desired location. The sum of the liquid and vapor pressure drops at the liquid-vapor interface gives the capillary pressure head. It is clear from the figure that the maximum pressure drop occurs at the left end of the evaporator. Even though the maximum tem-
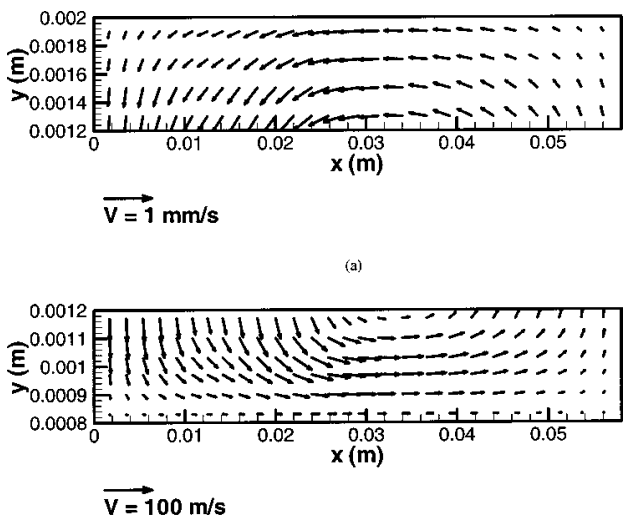

Fig. 7 Velocity vectors in the (a) wick and (b) vapor core at the mid plane of the heat pipe $(z / W=0.5$, with $15-15 W$ heat input and $d=5 \mathrm{~mm}$ ): note that the velocity scale in the two plots is very different. 


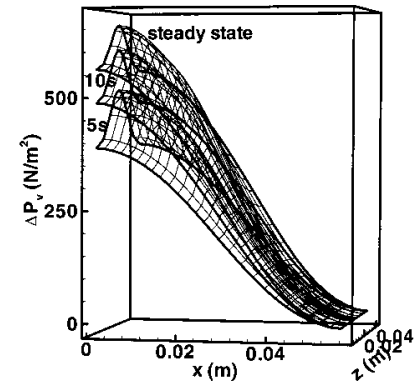

(a)

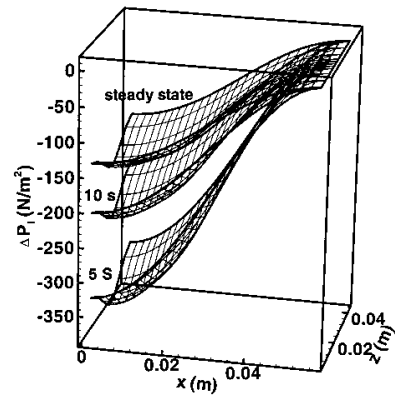

(b)

Fig. 8 Transient development of pressure drop in the (a) vapor, and $(b)$ liquid, at the liquid-vapor interface (heat input $=15-15 \mathrm{~W}, d=5 \mathrm{~mm}$ )

perature does not occur at the left end of the evaporator (as shown in Fig. 5), Fig. 8 shows that the maximum pressure drop is realized at the left end of the evaporator throughout the transient and at steady state.

In the following, the effects of varying the power input to the two heat sources, as well as the separation between the heat sources, on the temperature, velocity and pressure distributions in the heat pipe under transient and steady-state conditions are presented. The effects of these parameters on the overall performance of the heat pipe are also discussed.

Effect of Variation of Heat Input to the Heat Sources. The effect of changing the heat input distribution between the two heat sources (for a fixed total input power) on the temperature contours is shown in Fig. 9. Of the total input power of $30 \mathrm{~W}$, three cases with progressively increasing heat input to the right heat source are considered: (a) 15-15 W (baseline), (b) 10-20 W, and (c) 5-25 W. The end-to-end separation between the heat sources is held constant in this set of results. When the heat inputs to the two sources are equal (case a), the maximum temperature in the heat pipe $(311.9 \mathrm{~K})$ occurs at the center of the left heater. However, when the heat input to the heat source on the right is increased from 15 to 20 and $25 \mathrm{~W}$, the location of the maximum temperature (312.5 K for $10-20 \mathrm{~W}$ input and $314.2 \mathrm{~K}$ for 5-25 W input) shifts to the right heat source, closer to the condenser section.

Figure 10 shows the axial mass flow rate through the wick for the different heat input distributions considered in Fig. 9. The mass flow rate increases with distance away from the condenser end as mass is added by condensation of vapor. So also, the mass flow rate decreases as the evaporator is traversed from right to left due to evaporation of liquid. The effect of the increase in heat input to the right-side heat source is apparent in the reduction of mass flow rate to the left-side heat source in the 5-25 W distribution case. The mass flow rate through the left heater is not tripled when the heat input increases from $5 \mathrm{~W}$ to $15 \mathrm{~W}$ at this heater. This is because of the effect of heat spreading through the wall and the liquid wick.

Effect of Heat Source Separation. The effect of heat source

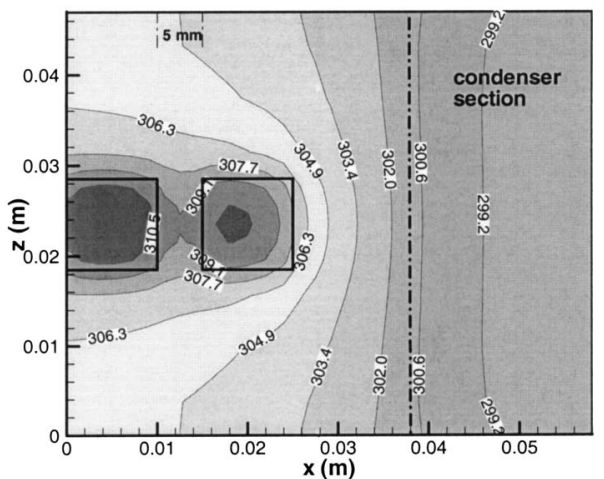

(a)

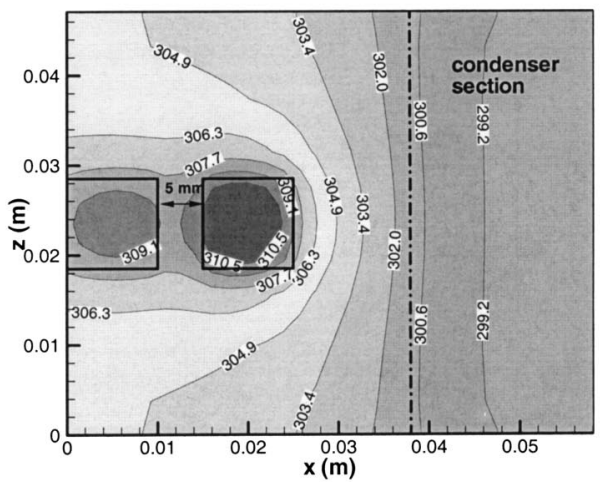

(b)

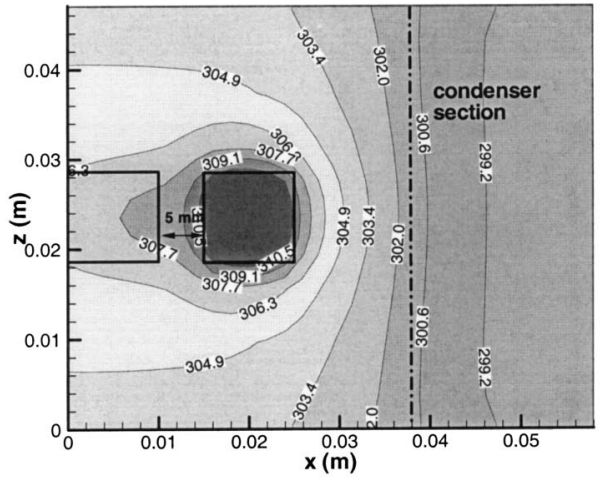

(c)

Fig. 9 Temperature contours on the wicked-wall of the heat pipe for heat inputs to the left and right heat sources of (a) 15-15 W, (b) 10-20 W, and (c) 5-25 W (d=5 mm)

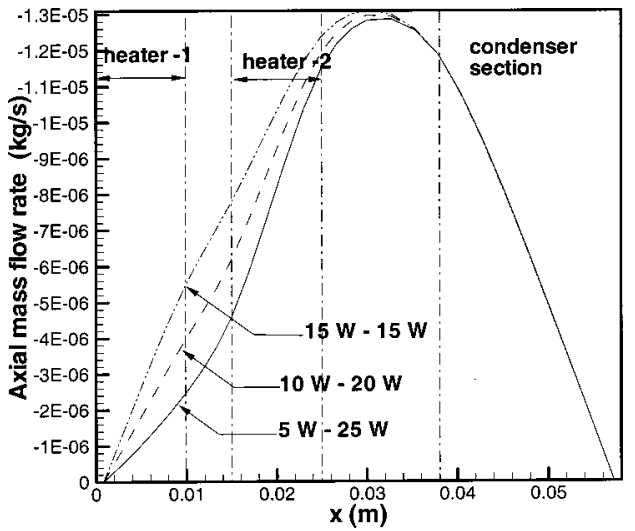

Fig. 10 Axial mass flow rate through the wick $(d=5 \mathrm{~mm})$ 


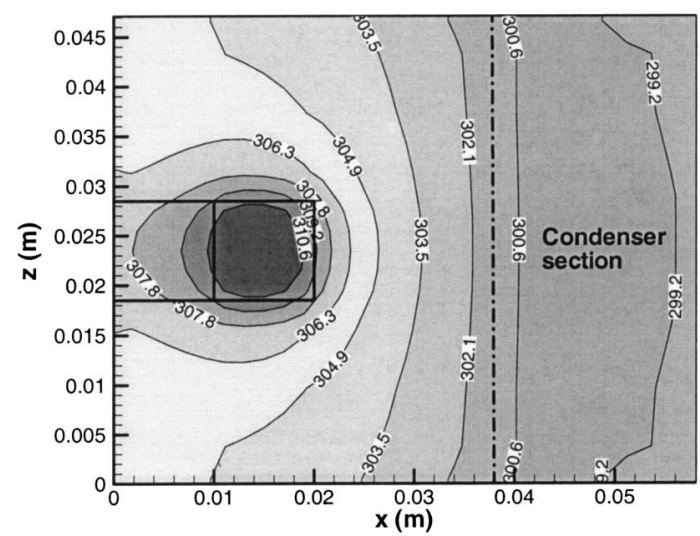

(a)

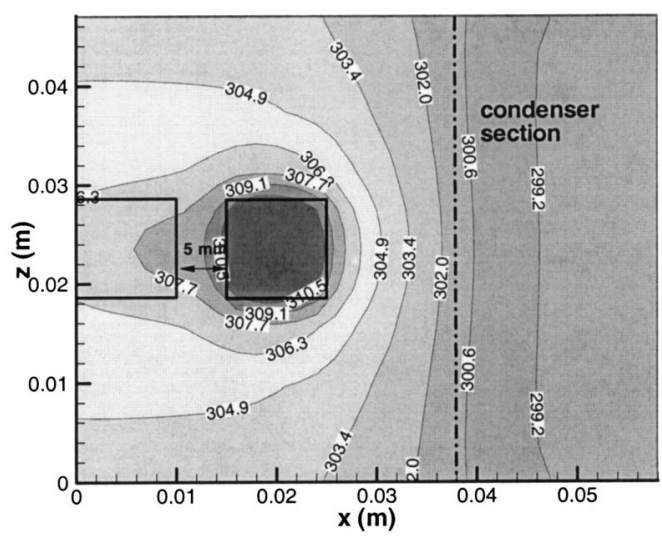

(b)

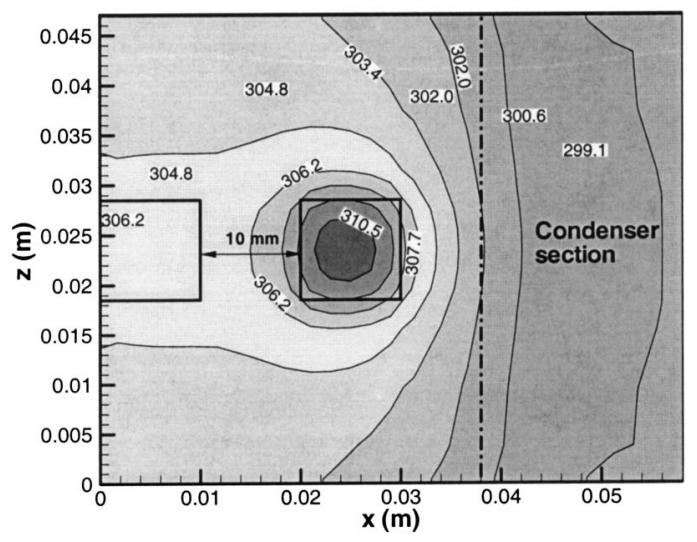

(c)

Fig. 11 Temperature contours in the liquid at the liquid-vapor interface for different separation between the heaters (heat input $=5-25 \mathrm{~W}$ )

separation is investigated next, with the power input to the two heat sources held constant at 5 and $25 \mathrm{~W}$ for the left and right sources, respectively. The heat source separation is varied through 0,5 and $10 \mathrm{~mm}$.

As expected, Fig. 11 shows that the maximum temperature always occurs at the center of the right heat source with the higher heat input. This maximum temperature reduces from $312.6 \mathrm{~K}$ to $311.4 \mathrm{~K}$ as the distance between sources is increased from 0 to 10 $\mathrm{mm}$. As the separation between the sources is increased, the source on the right gets closer to the condenser, explaining this drop in maximum temperature. This temperature dependence with

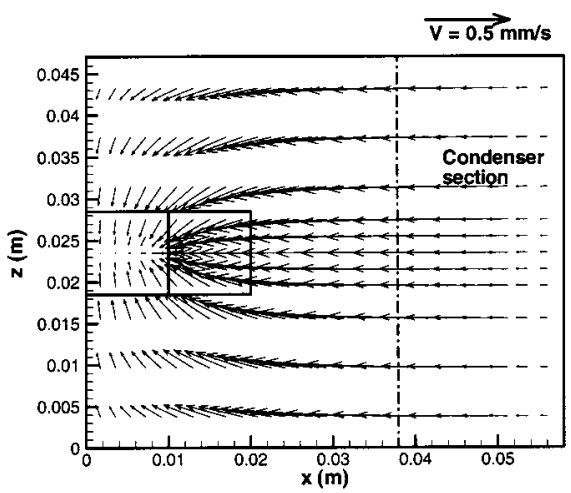

(a)

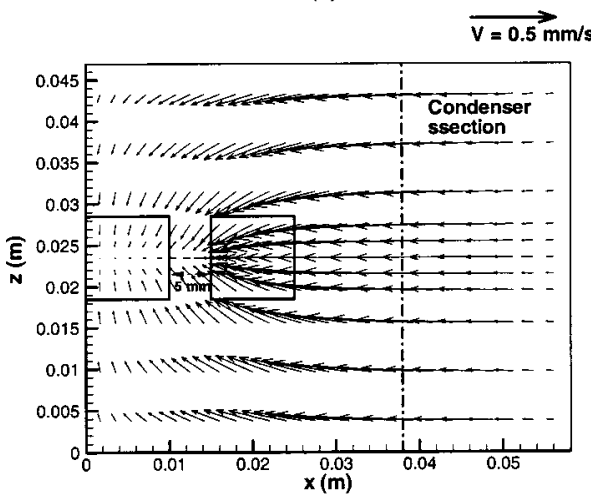

(b)

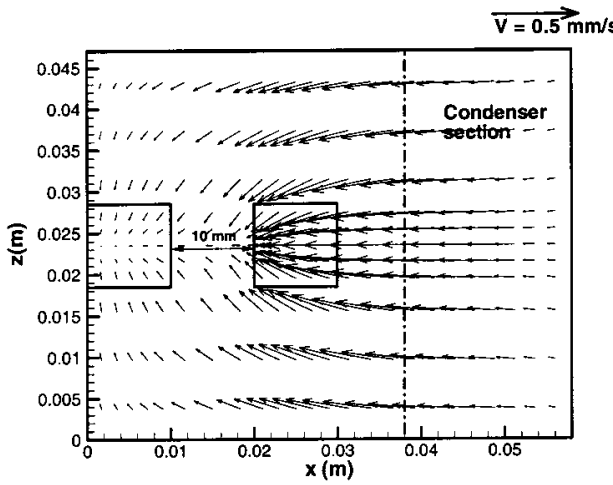

(c)

Fig. 12 Liquid velocity vectors in the wick near the liquid vapor interface for different heat source separations (heat input $=5-25 \mathrm{~W}$ ): (a) $\mathrm{d}=0$, (b) 5, and (c) $10 \mathrm{~mm}$.

respect to the location of the heat source with respect to the condenser illustrates the importance of axial diffusion through the wall and wick.

Figure 12 illustrates the effect of heat source separation on the mass flow rate through the evaporator. As the high heat input source moves closer to the condenser, the mass flow to the leftside heat source is significantly reduced. This is because of the effect of heat spreading into the condenser region through the wall and the wick when the distance between the heaters is increased. A change in heat source separation from $d=0$ to $10 \mathrm{~mm}$ results in a reduction of 54 percent in the mass flow rate to the left-side heat source. The temperature on the left end of the evaporator is decreased when the heat source separation increases, thus reducing the rate of evaporation under the left end.

The location of the maximum velocity at the interface corresponds to the location of the maximum interface temperature. Also, this $v$-velocity is higher as the heat source separation is 


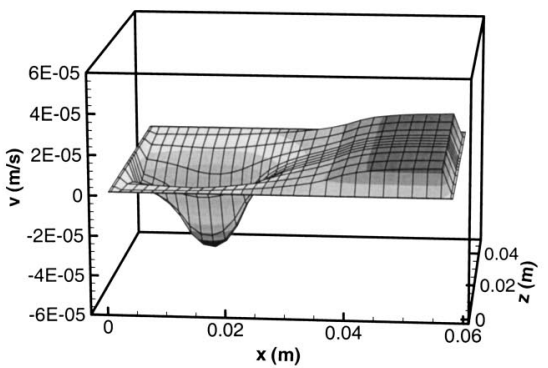

(a)

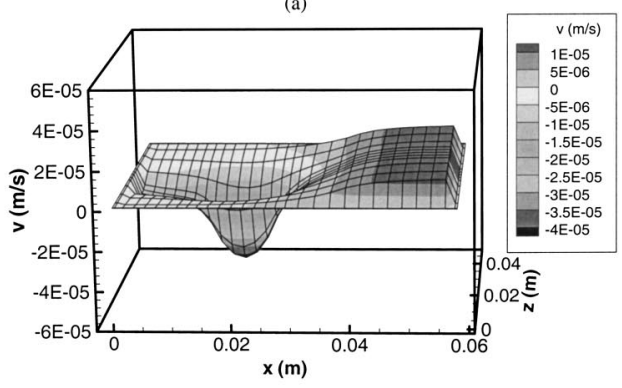

(b)

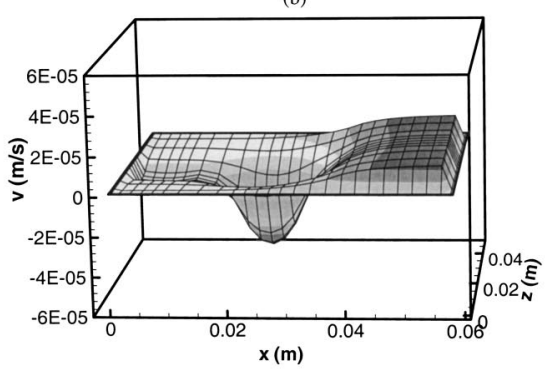

(c)

Fig. 13 Normal ( $v$-) velocities in the liquid at the liquid-vapor interface at different heat source separations (heat input $=5-25 \mathrm{~W}$ ): (a) $\mathrm{d}=0$, (b) 5 , and (c) $10 \mathrm{~mm}$. The shading denotes contours of $v$-velocity.

reduced, since the maximum wall temperature correspondingly increases. The $v$-velocity at the liquid-vapor interface is shown in Fig. 13 at the different heat source separations. As the higherpower heat source is moved closer to condenser, the actual "condenser section" penetrates deeper and deeper towards the evaporator section. The actual condensing and evaporating areas at the liquid vapor interface can be determined from Fig. 13.

Figure 14 shows the transient variation of the liquid and vapor pressure drop at the liquid-vapor interface. It is interesting to note that the location of the maximum pressure in the liquid and vapor changes during the transient. The mass flow rate in heat pipe increases during the transient period and reaches a maximum value at steady state. As the dynamic pressure loss increases in response to this increase in the flow rate, and becomes significant, the location of the maximum pressure drop shifts towards the left end of the evaporator. The location of the dryout region during transient startup would thus depend on the transient path adopted.

The axial variation of the liquid and vapor pressure drop at the interface at steady-state conditions is shown in Fig. 15. Once steady state is reached, irrespective of the location of the maximum temperature (and the maximum interface velocity), the maximum pressure drops in the liquid and vapor always occur near the left end of the evaporator. This is because of the significant velocities in the liquid and vapor encountered under the conditions of the present work, which lead to high dynamic pressure

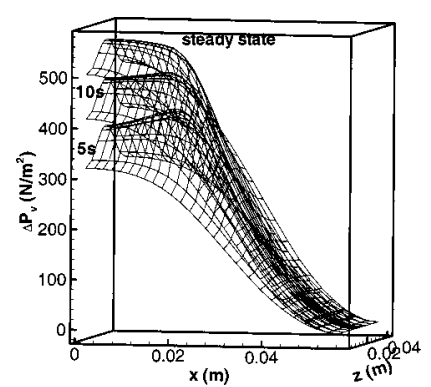

(a)

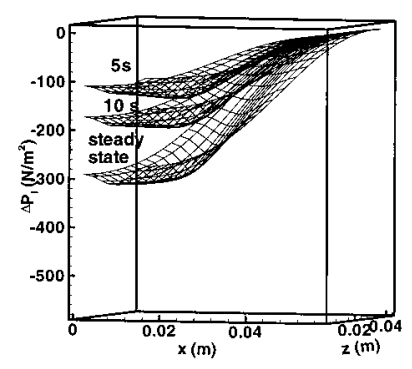

(b)

Fig. 14 Transient development of pressure drop in the (a) vapor, and (b) liquid, at the liquid-vapor interface (heat input 5-25 $W$ and $d=5 \mathrm{~mm}$ )

losses. When the heat source separation decreases, the mass flow rate to the left end of the evaporator increases (Fig. 12), as do the dynamic pressure losses as seen in Fig. 15.

In the absence of gravity, the sum of the liquid and vapor pressure drops give the total pressure drop at any axial location along the liquid-vapor interface. From Fig. 15 it is possible to determine the required capillary pressure drop by summing the maximum liquid and vapor pressure drops. From the expression for the capillary pressure drop, $\Delta P_{c}=2 \sigma / r_{p}$, it is possible to determine the pore radius of the wick that can provide the required capillary pressure drop necessary to prevent dryout. For instance, in the present cases, the steady-state $\Delta P_{c}$ is found to be 1021,883 , and $742 \mathrm{~N} / \mathrm{m}^{2}$ for the 0,5 , and $10 \mathrm{~mm}$ separation distances, respectively. The pore radii necessary to support these capillary pressure heads are thus $1.37 \times 10^{-4}, 1.58 \times 10^{-4}, 1.89 \times 10^{-4} \mathrm{~m}$, respectively. For a given pore radius, the present analysis helps to determine the time and location of dryout. The location of dryout is that at which the capillary pressure head has a maximum value. In

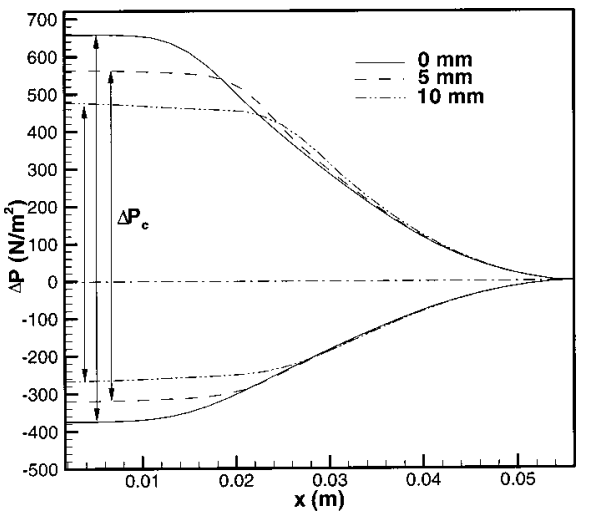

Fig. 15 Pressure drop in the liquid and vapor at the liquidvapor interface at different heat source separation distances (heat input 5-25 W, $z / W=0.5$ ) 
all the three cases studied, the maximum pressure head at steady state occurs at the left end of the evaporator, and this is the point where dryout would occur.

\section{Conclusions}

A complete, three-dimensional mathematical model has been developed to analyze the transient and steady-state performance of flat heat pipes, under the action of discrete multiple heat sources. The model accounts for the pressurization of the vapor core and the coupling of the continuity/momentum and energy equations in the wick and vapor regions. The analysis helps to determine the maximum pore radius of the wick allowable while still supporting the total pressure drop in a flat heat pipe. The location of dryout under transient and steady-state conditions can also be estimated.

The analysis highlights the importance of considering axial diffusion through the wall and wick in determining the temperature distribution in flat heat pipes. As the distance between multiple discrete heat sources increases, the maximum temperature in flat heat pipe decreases, resulting in lower liquid and vapor pressure drops.

\section{Acknowledgment}

The authors acknowledge the financial support of the members of the Cooling Technologies Research Center (www.ecn.purdue.edu/CTRC), a National Science Foundation Industry/University Cooperative Research Center.

\section{Nomenclature}

$$
\begin{aligned}
A & =\text { area, } \mathrm{m}^{2} \\
C & =\text { specific heat capacity at constant pressure, } \mathrm{J} / \mathrm{kg} \mathrm{K} \\
C_{E} & =\text { Ergun's coefficient, } 0.55 \\
d & =\text { end-to-end separation between heat sources, } \mathrm{m} \\
H & =\text { thickness of the heat pipe, } \mathrm{m} \\
h_{f g} & =\text { latent heat, } \mathrm{J} / \mathrm{kg} \\
k & =\text { thermal conductivity, } \mathrm{W} / \mathrm{m} \mathrm{K} \\
k_{\text {eff }} & =\text { effective thermal conductivity, W/m K } \\
K & =\text { permeability of the porous medium, } \mathrm{m}^{2} \\
L & =\text { length of the heat pipe, } \mathrm{m} \\
m & =\text { mass flow rate, } \mathrm{kg} / \mathrm{s} \\
m^{\prime \prime} & =\text { mass flux, } \mathrm{kg} / \mathrm{m}^{2} \mathrm{~s} \\
M & =\text { mass, } \mathrm{kg} \\
P & =\text { pressure, Pa } \\
q & =\text { heat flux, } \mathrm{W} / \mathrm{m}^{2} \\
R & =\text { gas constant, } \mathrm{J} / \mathrm{kg} \mathrm{K} \\
r & =\text { pore radius, } \mathrm{m} \\
t & =\text { time, } \mathrm{s} \\
T & =\text { temperature, } \mathrm{K} \\
u & =\text { longitudinal velocity, } \mathrm{m} / \mathrm{s} \\
v & =\text { transverse velocity, } \mathrm{m} / \mathrm{s} \\
V & =\text { velocity vector, } \mathrm{m} / \mathrm{s} \\
W & =\text { width of the heat pipe, } \mathrm{m} \\
w & =\text { transverse velocity, } \mathrm{m} / \mathrm{s} \\
x & =\text { axial coordinate; axial distance, } \mathrm{m} \\
y & =\text { transverse distance, } \mathrm{m} \\
\Delta t & =\text { time step, } \mathrm{s} \\
\Delta x & =x \text {-direction width of control volume, } \mathrm{m} \\
\Delta y & =y \text {-direction width of control volume, } \mathrm{m} \\
& =
\end{aligned}
$$

\section{Greek Symbols}

$$
\begin{aligned}
\mu & =\text { dynamic viscosity, } \mathrm{Ns} / \mathrm{m}^{2} \\
\rho & =\text { density, } \mathrm{kg} / \mathrm{m}^{3} \\
\varphi & =\text { porosity of the wick }
\end{aligned}
$$

$$
\sigma=\text { accommodation coefficient; surface tension, } \mathrm{N} / \mathrm{m}
$$

Subscripts

$$
\begin{aligned}
0 & =\text { reference } \\
a & =\text { adiabatic section } \\
c & =\text { condenser } \\
i & =\text { interface } \\
l & =\text { liquid } \\
m & =\text { mean value } \\
o p & =\text { operating pressure } \\
s & =\text { solid } \\
\text { sat } & =\text { saturation condition } \\
v & =\text { vapor } \\
w & =\text { wall }
\end{aligned}
$$

\section{References}

[1] Garimella, S. V., and Sobhan, C. B., 2001, "Recent Advances in the Modeling and Applications of Nonconventional Heat Pipes," Advances in Heat Transfer, 35, pp. 249-308, Chpt. 4.

[2] Tien, C. L., and Rohani, A. R., 1974, "Analysis of the Effects of Vapor Pressure Drop on Heat Pipe Performance," Int. J. Heat Mass Transfer, 17, pp. 61-67.

[3] Ooijen, V., and Hoogendoorn, C. J., 1979, "Vapor Flow Calculations in a Fla Heat Pipe," AIAA J., 17, pp. 1251-1259.

[4] Chen, M. M., and Faghri, A., 1990, "An Analysis of the Vapor Flow and the Heat Conduction Through the Liquid Wick and Pipe Wall in a Heat Pipe with Single or Multiple Heat Sources," Int. J. Heat Mass Transfer, 33, pp. 1945 1955.

[5] Issacci, F., Catton, I., Heiss, A., and Ghoniem, N. M., 1989, “Analysis of Heat Pipe Vapor Dynamics," Chem. Eng. Commun., 85, pp. 85-94.

[6] Cao, Y., and Faghri, A., 1990, "Transient Two-Dimensional Compressible Analysis for High-Temperature Heat Pipes with Pulsed Heat Input," Numer. Heat Transfer, Part A, 18, pp. 483-502.

[7] Issaci, F., Catton, I., and Ghoniem, N. M., 1991, "Vapor Dynamics of Heat Pipe Start-Up," ASME J. Heat Transfer, 113, pp. 985-994.

[8] Ambrose, J. H., and Chow, L. C., 1991, "Detailed Model for Transient Liquid Flow in Heat Pipe Wicks," J. Thermophys. Heat Transfer, 5, pp. 532-538.

[9] Tournier, J. M., and El-Genk, M. S., 1993, “A Heat Pipe Transient Analysis Model," Int. J. Heat Mass Transfer, 37, pp. 753-762.

[10] El-Genk, M. S., Huang, L., and Tournier, J. M., 1995, "Transient Experiments of an Inclined Copper-Water Heat Pipe," J. Thermophys. Heat Transfer, 9, pp. $109-116$.

[11] Zhu, N., and Vafai, K., 1998, “Analytical Modeling of the Startup Characteristics of Asymmetrical Flat-Plate and Disk-Shaped Heat Pipes," Int. J. Heat Mass Transfer, 41, pp. 2619-2637.

[12] Um, J. Y., Chow, L. C., and Baker, K., 1994, “An Experimental Investigation of Flat Heat Pipe," Fundamentals of Heat Pipes, 278, ASME, New York, pp. 21-26.

[13] Chesser, J. B., Peterson, G. P., and Lee, S., 2000, “A Simplified Method for Determining the Capillary Limitation of Flat Heat Pipes in Electronics Cooling," Proceedings of NHTC'00, 34th National Heat Transfer Conference, pp. $1-6$.

[14] Shimura, T., Sho, H., and Nakamura, Y., 2002, "The Aluminum Flat Heat Pipe Using Cyclopentane as Working Fluid," Inter Society Conference on Thermal Phenomena, IEEE, pp. 224-229.

[15] Chien, L., and Chang, C. C., 2002, "Experimental Study of Evaporator Resistance on Porous Surface in Flat Heat Pipes," Inter Society Conference on Thermal Phenomena, IEEE, pp. 236-242.

[16] Gillot, C., Avenas, Y., Cezac, N., Poupo, G., Schaeffer, C., and Fournier, E. 2002, "Silicon Heat Pipes Used as Thermal Spreaders," Inter Society Conference on Thermal Phenomena, IEEE, pp. 1052-1057.

[17] Xuan, Y., Hong, Y., and Li, Q., 2003, "Investigation on Transient Behaviors of Flat Heat Pipes," Exp. Therm. Fluid Sci., in press.

[18] Rightley, M. J., Tigges, C. P., Givler, R. C., Robino, C. V., Mulhall, J. J., and Smith, P. M., 2003, "Innovative Wick Design for Multi-Source, Flat Plate Heat Pipes," Microelectron. J., 34(3), pp. 187-194.

[19] Vadakkan, U., Murthy, J. Y., and Garimella, S. V., 2003, “Transient Analysis of Flat Heat Pipes," Procs. ASME Summer Heat Transfer Conference, Paper No. HT2003-47349.

[20] Grubb, K., 1999, "CFD Modeling of a Therma-Base(TM) Heat Sink," 8th International FLOTHERM User Conference.

[21] Carey, V. P., 1992, Liquid-Vapor Phase Change Phenomena, Hemisphere Publishing Corp., Washington DC.

[22] Patankar, S. V., 1980, Numerical Heat Transfer and Fluid Flow, McGraw-Hill, New York. 